\title{
Tools of the trade: practices and politics of researching the future in climate engineering
}

\author{
Sean Low ${ }^{1,2}\left[\right.$ - Stefan Schäfer ${ }^{1,3,4}$
}

Received: 31 August 2018 / Accepted: 3 April 2019 / Published online: 6 May 2019

(c) The Author(s) 2019

\begin{abstract}
Making sense of the implications of climate engineering approaches (solar radiation management, SRM; and carbon dioxide removal, CDR) at planetary scales occurs via a host of methods that calculate, project, and imagine the future in distinct ways. We take a systemic and synthesizing view of some of the (inter)disciplinary methods by which these futures are derived: climate and integrated assessment modeling, 'deductive' modes of social science inquiry, deliberative stakeholder engagement, and foresight-based scenarios. We speak to the epistemologies, objectives, and user communities surrounding these research practices, highlighting that different modes of constructing and interpreting evidence about an unformed future yield different kinds of results and signals for actions to be taken. We show how different methods for exploring 'futures' form an evolving history of how the risks of CE have been assessed (or constructed), and conclude by echoing calls for a stronger shared understanding of the practices and politics that underpin future-oriented research.
\end{abstract}

Keywords Futures $\cdot$ Climate engineering $\cdot$ Methodology $\cdot$ Research practice $\cdot$ Epistemology $\cdot$ Risk

\section{Future-based evidence making}

In the governance of climate change, understandings and decisions in the present are often informed by evidence that speaks of the future. Engineering planetary sunshades (solar radiation management, SRM) or carbon sinks (carbon dioxide removal, CDR; or of late, negative emissions technologies, NETs) are the latest entrants to the landscape of proposals for increasing humanity's capacity to cope with the effects of climate change. These approaches are often

Handled by Anne-Katrin Holfelder, Institute for Advanced Sustainability Studies, Germany.

Sean Low

sean.low@iass-potsdam.de

1 Institute for Advanced Sustainability Studies, Berliner Str. 130, 14467 Potsdam, Germany

2 Copernicus Institute for Sustainable Development, Utrecht University, Utrecht, Netherlands

3 Program On Science, Technology and Society, Harvard University, Cambridge, USA

4 Institute for Science, Innovation and Society, University of Oxford, Oxford, UK described as backed by proofs-of-concept, co-optable from components of existing systems, and sufficiently viable at small scales to merit discussion. They are, however, also often described as 'immature' - not (yet) existing as operational systems, and lacking technical and societal support. Advocacy and opposition thus has in the last decade been shaped by calculations, projections, and imaginings that richly depict the potential benefits and risks of these socalled forms of 'climate engineering' (CE). In doing so, such depictions frame the viability and desirability of different approaches.

We take as axiomatic that 'futures' are politically active resources. Insights into the shaping influences of conceptions of the future can be found in a rich literature on the sociologies of expectations (Borup et al. 2006), sociotechnical imaginaries (Jasanoff and Kim 2015), or visions (Grin and Grunwald 2000)—generally in science and technology debates, but also as these intersect with systemic governance issues such as security, health, and the global environment (Granjou et al. 2017). The objective of this contribution is to take a systemic and synthesizing view of the (inter) disciplinary methods by which futures are derived in the discourse on climate engineering. We do so as a point of entry for better understanding how futures are mobilized 
by scientific practice in an increasingly significant area of climate and sustainability politics. In speaking of methods, we highlight communities of practice, shared objectives and norms, epistemologies for generating evidence, and relative statuses of authority in the ecosystem of climate science and policy. A focus on methods also gives us an entry point into understanding how specific concerns emerge in relation to $\mathrm{CE}$ - that is, how different methods cast CE in their image by viewing it as a problem of, for example, changes in temperature and precipitation, interstate conflict and cooperation, the balancing of costs and benefits, or public support or rejection.

Why does this matter? In a field where much attention is directed to imaginary technologies and scenarios of usage, diverse disciplinary understandings inform how such objects are marshaled as evidence. But how does a method of evidence production shape the evidence it produces, or implicitly favor certain perspectives or actors? Our intent is to explore how different ways of making the future known shape the knowledge base upon which climate governance depends. For when particular futures gain a hold on the imagination of scientists, politicians and publics, they can come to structure expectations about what constitutes feasible and desirable courses of action, and shade from view or entirely foreclose alternative options.

We take a bird's eye view of climate and integrated assessment modeling, 'deductive' modes of social science, 'deliberative' stakeholder engagement, and foresight-based scenarios, introducing a number of dimensions for illuminating relationships and contestations between methods (the second section) before undertaking our overview (the third section). The final section synthesizes the links and comparisons established in the overview, showing how our analysis of different methods can be read as a history of how the risks of CE have been assessed (or constructed) - and therefore, how the bounds of the debate itself have come to be configured.

\section{Some dimensions of future mapping}

In this section, we lay out some characteristics by which we can differentiate methods engaged in mapping the concerns and challenges associated with engineering the climate- the following section on the methods themselves should be read in this light. Needless to say, our list of dimensions is neither exhaustive nor definitive-we derive them from an analysis of relevant literature, from long-standing participation in CE debates, and from an analytical sensibility based in science and technology studies (STS). Like the methods we discuss, these dimensions are geared toward a purpose; in our case, to allow for some systematic conclusions to be drawn about the mutual influences-and tensions-between modes of future-oriented research in $\mathrm{CE}$, and about the overall direction of that work.

The first differentiates between the processes of quantitative modeling approaches in natural and social science, and qualitative assessments generally deployed as part of social science scholarship. Modeling approaches use simulations based on advanced numeracy. These are simplified representations of reality extrapolated from an understanding of systemic laws (underpinning processes and trends, incentives and constraints) marshaled by quantitative variables and formulae, and that can be computed and aggregated in high numbers of scenarios (of a future moment) or pathways (leading to a future moment) - see the sub-section on "Climate models and integrated assessment models". The others are mixed-methods constructions (scenarios, frames, narratives) that, apart from eschewing a reliance on numeracy, defy easy coherence. Some display a similar logic to simulations, producing scenarios that extrapolate outcomes from systemic processes (see "Deductive reasoning in socio-political inquiry"). Others rely on stakeholder engagements, and on the proposed value of including a diverse range of disciplinary and political perspectives, for exploring challenges (see "Deliberative stakeholder engagement and foresight approaches").

The second is on the kind of challenges that a method is deployed to investigate surrounding the development or deployment of CE techniques. The dimensions of such inquiry can be (combinations of the) physical, techno-economic, and socio-political. Exploration of these challenges is often phrased as assessing 'benefits and risks', though a host of near-synonyms abound. Another way of thinking about it, however, is that methods (and by extension, the communities deploying them, for a variety of agendas and disciplinary understandings) will privilege certain criteria over others in defining risk. We might, however, also consider if, in the grand scheme of the CE research ecosystem, certain dimensions - that is, some mental and methodological ways of projecting risk—are made subordinate and subsequent to others.

The third parses the process of engaging with futures as deductive or deliberative. Deduction is a pervasive form of reasoning, where conclusions are reached 'downward' from a set of general assumptions rather than built 'upward' from particular instances. Disciplines across the humanities and the natural sciences provide much nuance on the definition and procedures of this concept. We ask the reader to indulge in a broad definition: if the laws of a system hold-say, the global climate system, or a system of (international) structures and actors, or some analogy of technological development-then if A happens, the analyst, with degrees of likelihood, can expect B, C, or D to result (or can, depending on her mental or computing capacity, trace a sequence of further assumptions and probabilities). From there a conversation 
opens up on the value of and motivations behind extrapolative, simulative, or probabilistic modes of thought. In the $\mathrm{CE}$ space, this includes efforts to gauge climatic as well as societal dimensions of CE; quantitative modeling and more qualitative methods; and disciplines ranging from climate science to economic and sociopolitical inquiry (see "Climate models and integrated assessment models", and "Deductive reasoning in socio-political inquiry").

A process set in opposition to 'deductive' thinking might be labeled as 'deliberative' - though this term (like deduction) is shorthand for other adjoining concepts. Attempts to cohere such a mode of investigation can particularly be found in frameworks of emerging technology governance that highlight deliberative engagement as part of the concept of 'anticipation' (see "Deliberative stakeholder engagement and foresight approaches"). The idea is that thinking about the future as part of a deductive paradigm can be prone to technocracy-there is an implicit emphasis on usable, technically focused projections, more so than on the processes, values, actors and agendas constructing them. The emphasis, then, should be less on what the future might be (however conditionally), and more on who is in the room to say so. Futures should be more explicitly treated as experimental, user-generated, and as inclusive as possible, highlighting the disciplinary and political understandings that create them, and generating avenues for action that navigate a wide array of aims and possibilities.

\section{Methods of future-oriented research}

\section{Climate models and integrated assessment models}

The Assessment Reports of the Intergovernmental Panel on Climate Change (IPCC) rely upon 'a vast machine' of computer models to simulate future climates-that is, they provide a legitimized mode for forming evidence on the risks of a warming planet, as well as for assessing the viability of strategies to reduce emissions (Edwards 2010). When climate change emerged as a subject of scientific inquiryand later, political ambition-an evolving array of model types became entrenched as the principle apparatus by which sense could be made of such a complex, systemic phenomenon. The importance of computer modeling, and the epistemology it represents, is held in place by continued advances in capacity, application to new issues, and mutual reliance between climatic projections and policy discussions.

Deriving the potentials of various CE proposals borrows heavily from the resources and historic credibility of the modeling enterprise. Climate models-underpinning the work of IPCC Working Group I on the physical science of climate change-have been used to estimate the climatic impacts of sunlight reflection methods (SRM). Integrated assessment models (IAMs) - assemblages that combine climate, land-use, energy systems, and economic components-are the vehicles of Working Group III assessments of mitigation options. These have been implicated in the conceptualizing of large-scale carbon removal (CDR) as an essential part of strategies for reaching the Paris Agreement's $2 \mathrm{C}$ target. Climate models and IAMs have different histories and applications in the CE space, but we address them together here because of epistemological overlaps in exploring the future.

Climate models were not originally intended to simulate targeted modifications of planetary reflectivity, but have been repurposed for gauging SRM's physical impacts (Wiertz 2015). This modeling activity has since generated one of the CE debate's largest bodies of the literature and authorship networks, relying heavily on the Geoengineering Model Intercomparison Project, or GeoMIP. Since 2011, research has become increasingly fine-tuned in terms of technology, regions, and impacts assessed (Kravitz et al. 2015). The principle of SRM modeling is straightforwardly deductive. Modelers adjust the reflectivity of various environmental systems as proxies for SRM approaches, resulting in projections of climate variables such as temperature, precipitation, sea level rise, and ozone. Calls for expanding modeling of devolved impacts on agriculture, fisheries, air pollution, and health are increasing (Irvine et al. 2016).

In the climate modeling literature, cooling the planet is broadly projected to reduce certain impacts associated with rising temperatures (Irvine et al. 2016). At the same time, significant variations and uncertainties-particularly on regional effects-depend on assumptions and choices made by researchers themselves. At the input stage, results are structured by the model used, and by the technology, amount, rate, term and location of deployment selected. Any modeler admits to this, but the details of these choices, spread over dozens of papers, are unfortunately if understandably elided. At the output stage, the reporting on benefits and risks, or the very translation work that makes results meaningful for further research or for societal deliberation, often then depends on the communicators in question, be they modelers or others. For example, Irvine et al. (2016) give a technical overview of SRM modeling that also functions as an optimistic prospectus, while McLaren (2018) provides a critical sociological and ethical interrogation.

IAM work on CDR, meanwhile, was not brought into conversations on $\mathrm{CE}$ until it was pointed out in the prelude to the negotiation of the Paris Agreement that the vast majority of Working Group III scenarios limiting temperature increases to $2 \mathrm{C}$ in 2100 relied on the rapid, largescale deployment of bioenergy carbon capture and storage (BECCS), an unproven chimera then on the fringes of CDR conversations. The presence of BECCS in resonant AR5 projections, it was argued, provides a backstop that 
scientifically legitimizes ambitious temperature targets as 'feasible', and introduces strange new signals to climate governance. There are concerns over the risks of deploying BECCS, such as land-use conflicts, carbon storage safety, or de-incentivizing emissions reductions, alongside fears that if there few other envisioned paths capable of meeting $2 \mathrm{C}$, then climate policy is being shoehorned into a future generated from these projections (e.g. Beck and Mahony 2018).

Interestingly, critical commentary also placed an ongoing focus on the role of the research groups built around IAM work as future-makers, resembling points made on the shaping choices of researchers in SRM modeling. The IAM community, it was argued, needs to be aware that their work does not neutrally assess options as much as actively frame their viability and necessity. More uncomfortably, modelers are argued to be complicit in a mode of IPCC assessment in which policy actors invested in the $2 \mathrm{C}$ target as a political benchmark functionally trade funding to IAM groups in return for evidence that sustains its viability (Geden and Beck 2014; Geden 2016; Anderson 2015). This, then, calls the impartiality of certain strands of research into question. These issues are further complicated by the fact that contestations over influential technical parameters occur largely within hidden modeling processes, and are often lost in translation during the creation of outputs for wider deliberation (Pindyck 2017). The IAM community disputes these characterizations, noting that they had consistently warned about over-relying on BECCS and submitted agendas for further research, before rather than in response to critical attention (Tavoni and Socolow 2013; Fuss et al. 2014). Moreover, they resist the depiction of BECCS as somehow fabricated for filling the gap between reality and climate ambition, arguing that IAMs do not advocate for particular climate strategies as much as simulate emissions pathways with alternative mixes of technology as a platform for policy discussions.

Modelers in either field argue that their work offers fact-grounded but experimental estimates of the future that imperfectly aggregate trend across complex physical and economic systems. The process emphasizes expert judgment, as well as 'inter-comparisons' (e.g. GeoMIP for SRM) where a comparison between a range of models aiming at common targets is argued to contextualise outliers and deliver conclusions with greater confidence. In this understanding, knowledge of climatic impacts of CE approaches or of barriers to deploying them, can be produced or improved by refining inputs or by running a greater diversity of scenarios. Stronger modeling capacity and further modeling applications are seen to improve understanding of certain dimensions of risk, and their simplified, often intentionally limited parameters have to be taken into account when applying modeling results to policy crafting.
These are fair conditions, but their limitations are worth considering. Climate models, for example, have been argued to be an 'inventive tool' in the design of SRM strategies, in which planetary sunshades are 'virtual technologies' constructed and framed strongly within the bounds allowed by modeling capacity (Wiertz 2015). They are also black boxes imbued with the credibility of the modeling enterprise, from which conflicting choices and results can be selectively emphasized. More critical scholarship notes that this combination of expert judgment and complex model structure allows for much freedom in shaping the boundsand results-of modeling scenarios. But choices contested within modeling communities require a high bar of basic literacy, translate poorly to non-specialist audiences, and may even distract from political agendas or biases that remain less investigated or revealed (e.g. Wiertz 2015 and McLaren 2018 for SRM; Beck and Mahony 2018 for BECCS). Criticisms of technocracy can hardly be limited to modelers; critics also do not deny the value of modeling work in certain domains. That said, there is a difference in emphasis on the role of the researcher. Critical scholarship, more so than modeling papers, emphasizes the political dimensions of research practice, and the myriad agendas and pressures surrounding climate science.

This focus on the construction of evidence through research practice is helpful when considering that modeling activity in the CE space explores a deliberately limited set of dimensions. SRM modelers note that the risks they assess are limited to climatic processes and impacts. Integrated assessment modelers are frank that BECCS-heavy scenarios in AR5 were calculated based on technical, economically efficient criteria for scaling up infrastructure, and deliberately bracket sociopolitical dimensions. Yet, both therefore contain bracketed conceptualizations-of 'risk' for SRM, or 'feasibility' for BECCS - that functionally emphasize the physical or techno-economic criteria that modeling infrastructure is able to portray, ahead of the societal dimensions of deployment. Such politically and historically 'thin' scenarios do not capture historic culpability, vulnerability, need, and capacity; as such, they demand solutions divorced from the context in which the snapshot emerged (McLaren 2018). For example, the scaling up of BECCS, in many AR5 scenarios commencing heavily during the 2030s, assumes facilitating conditions on a global level and elides inequities in technological capacity and (carbon) geopolitics. This would be a deceptive basis upon which to build a case for BECCS, given resilient controversies surrounding the production of biomass for energy, or carbon capture and storage.

There is a further concern that scenarios can signal the need for politics to catch up to, or strongly avoid, the modeled reality. This is complicated by ambiguities surrounding the intents of modeling for explicitly providing decision-making support. IAM work-more established as 
a science-for-policy enterprise than SRM modeling due to its role in WGIII work in the IPCC process-tends to frame itself as neutral 'map-making', following the 'policy relevant but not policy prescriptive' ethos of the IPCC (Edenhofer and Minx 2014); the signaling implications of their 'maps' for expectations in climate governance, however, are highlighted in Beck and Mahony (2018). In contrast, SRM modeling networks have no common platform. GeoMIP's earlier efforts were geared more to model validation than policy; bluntly designed to induce strong impacts in the earth system to garner broad understandings of engineered climates, rather than reflect what might be climatically or politically 'desirable' (however this is to be defined). Some modelers have argued that scenarios assuming stronger mitigation and moderate SRM provide more tempered and realistic results for policy deliberation (Keith and MacMartin 2015). But are the conclusions of idealised studies deployed in political settings in a manner that exceeds their mandate? If so, what are the responsibilities of those involved-generators (e.g. modelers), translators (expert networks in climate governance), and audiences (civic and policy communities)?

Tensions between the purposes of modeling for improving systems understandings, calibrating modeling practice, or providing a workable basis for informing climate policy; or alternately, between the grounding of modeling outputs in real-world processes and their extrapolation into more fantastic possibilities, remain unresolved dimensions of this mode of research. But that modeling has both value and limitations in structure and application is not in dispute, neither by its practitioners nor by adjoining networks of (critical) experts. In what follows, we explore whether there is some disproportionate importance given to the epistemologies and practices of futures assessment represented by modeling in the $\mathrm{CE}$ research ecosystem, whether there are efforts to change these logics in research practice, and if these efforts can fruitfully co-exist.

\section{Deductive reasoning in socio-political inquiry}

While integrated assessment models do represent the social world in certain constrained ways, we now enter an area in which the focus is placed squarely on 'the social.' No method for exploring the sociopolitical dimensions of $\mathrm{CE}$ approaches is as dominant as modeling is regarding climatic effects. In approaching those dimensions, however, the methodologies examined here are in some ways epistemologically similar to the logics underpinning computer simulations: again, what we refer to as a 'deductive' approach. Expanded into social inquiry, dynamics are deduced from an initial set of starting conditions following the logic of the given methodology; this is a common but contested approach across economics, political science, and international relations. The latter pair of disciplines has imported key assumptions, and even statistical and modeling approaches, from economics (where influences have been traced further back to attempts at modeling social inquiry after the principles of physics) in the guises of rational choice theory and its offshoots (Bernstein et al. 2000). Through the application of those approaches, deductive thinking is a general presence in discussions of the 'social impacts' that CE approaches, as well as other fields of emerging sociotechnical systems, may have, despite criticism of such thinking from social scientific and humanist disciplines such as science and technology studies (e.g. Bijker et al. 1987).

One prominent vein is interested in the international political dynamics around SRM, forming a body of gametheoretic modeling studies that simulate the strategic actions of states regarding the development or deployment of SRM (Harding and Moreno-Cruz 2016), with implications for some outcome of interest to the study: for example, the formation of coalitions of SRM-capable states in Ricke et al. (2013), environmental treaty formation in Millard-Ball (2012), or emission reductions in Urpelainen (2012). These calculations unfold according to some set of covering laws: notably, states are represented as rational, strategic and unitary maximizers of benefits and minimizers of costs, following the concept of a 'homo oeconomicus' imported from microeconomic theory. Often, knowledge on the physical impacts of SRM deployments generated via climate modeling efforts serves as input for informing state preferences.

By giving a 'parsimonious' account of international political dynamics, such exercises can explain and, by extension, project outcomes with some predictive capacity precisely because of their high level of abstraction-or so proponents argue. Summarizing conclusions are difficult to reach due to differing aims: Urpelainen (2012) and Millard-Ball (2012) point out consequences of unilateral SRM on mitigation efforts; Ricke et al. (2013) conclude that a small-aspossible club of first-moving states will have an incentive to exclude new members that might upset their established preferences. To non-specialists, such exercises can appear based on highly simplified assumptions, and removed from the concerns that more qualitatively oriented scholarship takes to be at work in international politics. These dynamics of justification and critique can be observed regarding other modeling and simulative activities-for example, on the emergence of BECCS as a strategy for mitigation in integrated assessment modeling scenarios.

Unlike the use of climate and integrated assessment models, a critical summary and interrogation of this body of modeling work and its implications has yet to be undertaken. Some critiques would likely be imported (and contested by economic modelers): Abstracting complex societal trends and dynamics via numeracy (however advanced); the eliding of influential choices on modeling parameters made by researchers (however unintentionally); the relevance of 
politically 'thin' work that results from simplifying context, time, and value-specific concerns (however necessarily for calculability and parsimony). Whether or not these game theoretic studies present potentials for building momentum behind realities they represent is another matter (e.g. BECCS in climate discussions); they do not appear to have had significant traction beyond internal debates in CE research networks. It is, perhaps, a space to watch.

Deductive reasoning is also found in less formalized analyses (as opposed to the highly formalized nature of game theory) regarding the politics of CE deployment, generally grouped within international relations or political science literatures. Neither discipline professes to be in the business of prediction; yet it is quite common to establish systemic understandings of the driving motivations and dynamics of politics that can then be presumed to shape actions and effects. What binds these otherwise disparate studies together is the understanding that future dynamics can be extrapolated from the assumption that SRM or CDR will grow up in a world embodied by particular problem structures-some understanding of the international system, some logic of conflict potential, some knowledge about environmental or technological consequences- that hold true for mapping its future politics.

For example, Horton and Reynolds (2016) call for studies utilizing leading international relations theories (e.g. realism, institutionalism, liberalism, and constructivism) to help structure thinking on the potential intersections between CE deployment, mitigation efforts, conflict, north-south relations, and governance challenges. Many security studies similarly rely on a systematic understanding of the motivations and constraints facing international actors to deduce implications for conflict over CE, implying that deployment would follow existing logics of 'potentials for direct conflict' like resource scarcity (Maas and Scheffran 2012), or that the promise of doing it would breed systemic brinksmanship in climate politics (the 'security hazard', Corry 2017). Studies can rely implicitly upon knowledge about environmental and technical consequences or 'side effects' to deduce political implications (e.g. Zürn and Schäfer 2013). Indeed, it is often the supposed environmental impacts that get first mention: for example, for SRM, changing temperature and precipitation patterns. For some, this sequencing is explicitly desirable, lest, to paraphrase Victor et al. (2013), the politics of geoengineering get far ahead of the science. This has similarly often been the case for assessments of governance and policy options; early governance proposals tended to emphasize management of physical risks, and 'tailor the amount of scrutiny to the scale' thereof (Lin 2015, p. 2538).

That environmental and climatic consequences of human activity have political knock-ons, and that systemic structures shape distributed outcomes, is seldomly contested in principle. Disagreement with these assumptions is based more on the priority thought to be given to technical and physical criteria of risk, or a perceived disposition of deductive social inquiry to expert-driven narratives and technocratic research, than on the notion that they are wrong in principle. In what follows, we trace one strand of pushback emerging against research practices that facilitate these modes of thinking.

\section{Deliberative stakeholder engagement and foresight approaches}

If the works of the previous section represent a 'deductive' mode of social science, then a burgeoning field of 'empirical' social science (Burns et al. 2016) posits that understandings of concerns and values regarding future risks and challenges can be sourced from engagements with scientific, policy, and civic stakeholders. From there, however, procedures and intents underpinning engagement work diverge. A network of (largely) UK-based scholars and practitioners highlight that two distinct waves of stakeholder engagements can be observed. In the first wave, it was argued, procedures were functionally entrenching SRM and CDR approaches as 'policy objects' (the accused include, e.g. Ipsos 2010; Mercer et al. 2011). Questions were asked, and discussion configured, around technical dimensions and thresholds of effectiveness, safety and cost that purportedly made CE approaches more researchable or actionable for the projected desires of policy-makers, disaggregated into individual technologies for 'differentiated governance', and with increased examination of stages of research or 'reduction of uncertainties' rather than broader social and ethical questions (Corner et al. 2013; Owen 2014).

Engagements of a so-called 'Second Wave' would utilize deliberative exercises-described generally as innovative dialogues highlighting different perspectives in exploring futures, with minimal prefacing work by experts. This would ideally create a space for discussing CE's means and ends in an open-ended, substantive manner, while 'un-framing' them as policy objects (for a summary of such exercises, see Bellamy and Lezaun 2017). Significantly, this body of work invoked the principles of 'anticipatory governance' (Guston 2014), and 'responsible research and innovation (RRI)' (Stilgoe et al. 2013)—deliberative and future-oriented frameworks for the governance of emerging technologies. Both had previously seen concerted application in nanotechnology debates, and can be seen as an importation, by its practitioners, of an evolving toolkit of governance concepts and research practices from one realm of emerging techno-science into another (for a history of this 'amalgam of ideas', see Burget et al. 2017).

Methodologically, advocates of these frameworks contend that the current paradigm in future-oriented research places an undue focus on 'outcomes' rather than 'processes': 
that is, on the accuracy and usability of future projections of technology for policy, rather than on the epistemologies and choices on which these are pieced together; and on public engagement as a kind of reporting mechanism for audiences after-the-fact, rather than a deliberative activity from the outset that helps inform the objectives of scientific work. The argument is that this paradigm privileges and elides the role of 'key enactors' in setting and framing risks, reserving capacity to frame the boundaries of the debate for particularly invested constituencies while simultaneously portraying this process as apolitical (Owen 2014). Substantively, RRI practitioners in the CE space set themselves up against a reliance on technical knowledge as a baseline for defining societal challenges, or framing $\mathrm{CE}$ approaches as a narrow response to climate change rather than game-changing endeavors in their own right (Bellamy and Lezaun 2017; Foley et al. 2018).

One can admire the mission statement of RRI while interrogating its execution. Some have observed that the publications of this 'Second Wave' of engagements produce conclusions that counter-frame the viability and desirability of $\mathrm{CE}$ approaches as successfully as the framers they seek to counteract (Heyward and Rayner 2013; Schäfer and Low 2018). Bellamy et al. (2013), as a typical example of 'Second Wave' work, concludes that when engagements focus on more expansive societal concerns rather than on technical questions of cost and efficiency, participants tend to de-prioritise CE approaches. Macnaghten and Szerszynski (2013) more forcefully point to the "centralising and autocratic social constitution' of sunlight reflection methods, and question if it is compatible with democratic governance. Heyward and Rayner (2013) argue Macnaghten and Szerszynski's conclusions reflect a 'curious asymmetry', in which these characterizations are applied to forms of CE, yet not uniformly so to a variety of other governance proposals with similarly global, centralizing implications. The implication is that some RRI practitioners in this space, in seeking to 'unframe' climate engineering and retard its lock-in as a set of policy options, can be quieter on their own framing choices.

There is a larger point to be made, however obvious. RRI is not just a procedural framework for bettering participation; it is an umbrella concept for sets of political activities, representing the agendas and logics of particular networks in specific areas of emerging technology assessment, as well as particular conceptions of the proper relationship between science and society. The political may influence how the procedural is developed and executed, and to focus on the procedural alone de-politicises RRI as a concept and its practitioners as actors (see Van Oudheusden 2014). Engagements and critiques invoking RRI in the CE space focus more on interrogating the actors and signaling effects of modes of inquiry deemed to operationalize
CE approaches (e.g. prioritizing technical metrics over societal and normative questions) or elide the shaping influences of researchers (e.g. in modeling), than its own practice and politics. One need not devalue their work while asking the question of who is watching the watchers.

An adjacent corner of this ad-hoc field of deliberative methods requires its own mention, due to nuances in history and application. 'Foresight' approaches have recently found a limited traction in the CE space: predominantly (though not exclusively) as scenario-building exercises, and increasingly (though not initially) under the rubric of anticipatory frameworks. Long practiced as a set of prognostic and planning tools in military and business settings, foresight struggled for acceptance in the social sciences in earlier guises as 'futurology' or 'future studies'. However, overlaps were established between foresight practice and scholarship examining the shaping effects of claims to the future in emerging techno-science fields, and incorporated as a principal component of 'anticipatory governance' ('Foresight' in Guston 2014) and later in RRI ('Anticipation' in Stilgoe et al. 2013). Both frameworks invoke the use of scenario work-emphasizing its potential to enhance deliberation and critical reflection amongst participants-to map future-making processes.

Scenarios, in this understanding, reject probabilistic forecasting in favor of small sets of futures that are rich in sociopolitical detail, highly differentiated (or 'alternative') and easily comparable, and are developed deliberatively between diverse viewpoints. Scenarios are in turn supposed to be experimental: provoking reflection by participants on specific conceptions of future threats and opportunities, on why these conceptions (but not others) made the cut, and on strategies that might be resilient against or adaptable to a wide variety of possible outcomes rather than tailored to a more limited set of predictions (Vervoort and Gupta 2018). Most exercises in the CE space were developed in expert-driven workshops with small participation numbers, developing 'explorative' scenarios that reflect on the challenges presented to-and by-efforts to govern SRM or CDR development under a variety of environmental and societal pressures (Low 2017b). We might note that early CE scenarios were motivated by older principles of foresight rather than by RRI. Alongside deliberative engagement exercises, scenario work began to invoke RRI as that framework became popularized (Low 2017a; Bellamy and Healey 2018).

Whether conducted under the spirit or the letter of RRI, foresight's practitioners pose it as a corrective logic to inertial modes of inquiry that lend greater credence to evidence grounded in hindsight, and portray researchers as aloof from rather than constitutive of the futures they assess. Both are points of view antithetical to the practiceoriented prospection that foresight represents (Selin 2008). 
The framing effects of this small collection of exercises on the wider debate, however, are for now minimal. For a start, the field suffers from low visibility, and has not generated resonant conclusions on risk or governance that one might examine for motive and effect. Scenarios sometimes turn out too outlandishly to be actionable or recombine risks already derived in other studies. Moreover, its objectives and conclusions are internally incoherent. Practitioners are divided on the use of foresight for creating 'actionable' knowledge for strategic framing and policy guidance, or for communicating between and interrogating participating perspectives as part of 'community learning' (Talberg et al. 2018; Gabriel and Low 2018). However, as a deliberative tool, foresight shares much with (and is often used for) stakeholder engagement - this is where it may currently hold more credibility in the CE space. As with engagement exercises conducted under the RRI banner, one can question if foresight applications fulfill ambitions of 'opening up' the debate to more plural processes, or produce results with veiled political and normative commitments.

\section{A shared understanding of futures research}

Our intent here has been to question if research methods produce assumptions that structure how futures are generated and acted upon in the present. What are the kinds of risk highlighted by those futures, and positioned as relevant concerns for research and policy in the present? What are epistemologies, expertises, and agendas that they come tied up with, and what actors do they privilege? In short: how do methods and their users configure the bounds of the debate? From the above analysis, we distil some underlying currents in the construction of climate engineering futures. What follows is not intended as definitive, or as a strict dichotomy; however, we believe that it captures relevant differences in broad strokes.

First, the dimensions represented by modeling - the capacity of numeracy to capture and simulate complex dynamics, the functional focus on physical and technoeconomic aspects, characterizations as science 'proper'often occupy a position of epistemological primacy. We can consider, for example, the expansion of modeling logics into assessments that focus upon political and societal questions, or (more tenuously) the resilience of deductive reasoning across research practice. Moreover, and with particular relevance to SRM, socio-political assessmentsin game theory, deductive inquiry into risk, even some engagement work-position politics as efforts to navigate the 'climates' generated by physical science modeling.

This is not to write off the usefulness of such simulations. These can yield imperfect but valuable observations about the environmental or technical dimensions that they are designed to explore; indeed, one can reasonably argue that different epistemologies and practices of assessment tackle different areas of the puzzle. Models, one might note, cannot determine public values any more than deliberative engagement can determine the physical science of precipitation; the challenge is for the results of different areas of investigation to fruitfully inform each other. Yet, this proposed division of labour might be a little simplistic: All research practices (and users) are already engaged in a larger system where judgment is passed, in ways that defy simple boundary-drawing between methods and expert communities, on the viability and desirability of kinds of CE. Plainly put: the use of research often exceeds the bounds of its design.

The question critics (and the authors as well) raise is whether limited conceptions and calculations of risk, and the futures they frame, are inertially and disproportionately prominent within CE's research ecosystem because they are more amenable to modeling practices. This is seen to be amplified by other perceived factors: If modeling, as a mode of futures-exploration, retains a particular, historic resonance and credibility in climate science and governance; if the CE research enterprise is, as is the case for much work in emerging fields of science and technology, characterized strongly by the expectation to create actionable or policy relevant evidence; and if expert-driven assessment, however unintentionally, often leans toward technocracy. In partial response to these concerns (within and outside of CE), more deliberative practices of social inquiry-increasingly marshalled under the banner of RRI or 'anticipatory' assessment of immature technological systems-have developed a growing presence. These attempts to present alternatives by repositioning politics as constitutive of, and not subordinate to, science. Deliberative engagement, at least in mission statement, presents an increasing variety of civic and policy audiences with the opportunity to frame the implications of engineered climates on their own terms. But although posing corrective measures to technical and technocratic future-making, some actors in this space have been critiqued as bringing with them their own normative commitments regarding the desirability of the climate engineering enterprise. The observation, then, that research practice is political is not applicable only to modeling work. Approaches for bettering process such as RRI need to be examined as tied to the forms of expertise, agendas, and blind spots of its practitioners, as much as the activities that they interrogate.

All this is to point out that practitioners in this space can and should work to enhance complementarity between methods and users-not simply by 'putting them in their place', or allowing different methods to assess different questionsbut by also building a shared understanding of the practices and politics that underpin future-oriented research. This, ideally, might allow for more fluid, mutual access between 
disciplinary communities, or with stakeholders from a variety of demographics and polities, in shaping objectives and methods of research. Efforts across disciplines to clarify the intents and limits of various methods remain low hanging fruits, as is deepening the interdisciplinarity of research projects (for a critique of the imperfect degree of mutual learning in assessments, see Foley et al. 2018). Understanding 'boundary work' is especially useful for cross-disciplinary learning: the idea that concepts ostensibly common to different expert, civic, or policy communities-for example, 'deductive' and 'deliberative', 'risk' and 'feasibility', 'expert judgment', 'scenarios', 'futures', and even 'sustainability' are likely understood and practiced with tribal nuances and agendas (e.g. Shackley and Wynne 1996).

Illustrations of research practice with a stronger blending of disciplines might also be helpful. Much foresight work in this space, for example, combines discussion of climatic, societal, and political trends to build futures that reflect the forms of expertise and concerns of diverse participants-a combination of deliberative engagement with elements of simulative work for a more participatory kind of scenario construction. Also of interest to the authors are proposals to integrate principles of 'deliberation' and 'anticipation' (again, research generated jointly between experts and publics, that highlights rather than elides non-technical perspectives) into climatic, game theoretic, or integrated assessment modeling - precisely the kind of knowledge production where a high bar for literacy creates a high barrier to entry. Greater attention thus needs to be paid not just to the outcomes of analyses-what the benefits and risks of future technologies supposedly are-but to the methodological processes through which such knowledge is produced, to how these structure our knowledge in ways that illuminate certain benefits and risks over others, and to the building of shared epistemologies and practices that explore different futures of climate, society, and sustainability in reflexive and experimental ways.

Open Access This article is distributed under the terms of the Creative Commons Attribution 4.0 International License (http://creativeco mmons.org/licenses/by/4.0/), which permits unrestricted use, distribution, and reproduction in any medium, provided you give appropriate credit to the original author(s) and the source, provide a link to the Creative Commons license, and indicate if changes were made.

\section{References}

Anderson K (2015) Duality in climate science. Nat Geosci 8:898-900 Beck S, Mahony M (2018) The politics of anticipation: the IPCC and the negative emissions technologies experience. Glob Sustain $1: 1-8$

Bellamy R, Healey P (2018) 'Slippery slope'or 'uphill struggle'? Broadening out expert scenarios of climate engineering research and development. Environ Sci Policy 83:1-10
Bellamy R, Lezaun J (2017) Crafting a public for geoengineering. Public Underst Sci 26:402-417

Bellamy R, Chilvers J, Vaughan NE et al (2013) 'Opening up' geoengineering appraisal: multi-criteria mapping of options for tackling climate change. Glob Environ Change 23:926-937

Bernstein S, Lebow RN, Stein JG, Weber S (2000) God gave physics the easy problems: adapting social science to an unpredictable world. Eur J Int Relat 6(1):43-76

Bijker WE, Hughes TP, Pinch TJ (1987) The social construction of technological systems: new directions in the sociology and history of technology. MIT Press, Cambridge

Borup M, Brown N, Konrad K et al (2006) The sociology of expectations in science and technology. Technol Anal Strateg Manag 18:285-298

Burget M, Bardone E, Pedaste M (2017) Definitions and conceptual dimensions of responsible research and innovation: a literature review. Sci Eng Ethics 23:1-19

Burns ET, Flegal JA, Keith DW et al (2016) What do people think when they think about solar geoengineering? A review of empirical social science literature, and prospects for future research. Earth's Future 4:536-542

Corner A, Parkhill K, Pidgeon N et al (2013) Messing with nature? Exploring public perceptions of geoengineering in the UK. Glob Environ Change 23:938-947

Corry O (2017) The international politics of geoengineering: The feasibility of Plan B for tackling climate change. Secur Dialogue 48(4):297-315

Edenhofer O, Minx J (2014) Mapmakers and navigators, facts and values. Science 345:37-38

Edwards PN (2010) A vast machine: computer models, climate data, and the politics of global warming. MIT Press, Cambridge

Foley RW, Guston D, Sarewitz D (2018) Towards the anticipatory governance of geoengineering. In: Blackstock JJ, Low S (eds) Geoengineering our climate? Ethics, politics and governance. Routledge, London

Fuss S, Canadell JG, Peters GP et al (2014) Betting on negative emissions. Nat Clim Change 4:850-853

Gabriel J, Low S (2018) Foresight in climate engineering. In: Blackstock J, Low S (eds) Geoengineering our climate? Ethics, politics, and governance. Routledge, London, pp 218-222

Geden O (2016) The Paris Agreement and the inherent inconsistency of climate policymaking. Wiley Interdiscip Rev Clim Change 7:790-797

Geden O, Beck S (2014) Renegotiating the global climate stabilization target. Nat Clim Change 4:747-748

Granjou C, Walker J, Salazar JF (2017) The politics of anticipation: on knowing and governing environmental futures. Futures 92:5-11

Grin J, Grunwald A (2000) Vision assessment: shaping technology in 21 st century society. Springer, Berlin

Guston DH (2014) Understanding 'anticipatory governance'. Soc Stud Sci 44:218-242

Harding A, Moreno-Cruz JB (2016) Solar geoengineering economics: from incredible to inevitable and half-way back. Earth's Future 4:569-577

Heyward C, Rayner S (2013) A curious asymmetry: social science expertise and geoengineering. Climate Geoengineering Governance working paper 7 . http://geoengineering-governance-resea rch.org/perch/resources/workingpaper7heywardrayneracuriousa symmetry.pdf. Accessed 29 Apr 2019

Horton JB, Reynolds JL (2016) The international politics of climate engineering: a review and prospectus for international relations. Int Stud Rev 18:438-461

Ipsos MORI (2010) Experiment earth? Report on a public dialogue on geoengineering. https://goo.gl/YrEspL. Accessed 29 Apr 2019 
Irvine PJ, Kravitz B, Lawrence MG et al (2016) An overview of the Earth system science of solar geoengineering. Wiley Interdiscip Rev Clim Change 7:815-833

Jasanoff S, Kim S-H (2015) Dreamscapes of modernity: sociotechnical imaginaries and the fabrication of power. University of Chicago Press, Chicago

Keith DW, MacMartin DG (2015) A temporary, moderate and responsive scenario for solar geoengineering. Nat Clim Change 5:201-206

Kravitz B, Robock A, Tilmes S et al (2015) The geoengineering model intercomparison project phase 6 (GeoMIP6): simulation design and preliminary results. Geosci Model Dev 8:3379-3392

Lin AC (2015) The missing pieces of geoengineering governance. Minn Law Rev 100(6):2509-2576

Low S (2017a) Engineering imaginaries: anticipatory foresight for solar radiation management governance. Sci Total Environ 580:90-104

Low S (2017b) The futures of climate engineering. Earth's Future 5:67-71

Maas A, Scheffran J (2012) Climate Conflicts 2.0? Climate engineering as a challenge for international peace and security. Secur Peace 30:193-200

Macnaghten P, Szerszynski B (2013) Living the global social experiment: an analysis of public discourse on solar radiation management and its implications for governance. Glob Environ Change Hum Policy Dimens 23:465-474

McLaren DP (2018) Whose climate and whose ethics? Conceptions of justice in solar geoengineering modelling. Energy Res Soc Sci 44:209-221

Mercer AM, Keith DW, Sharp JD (2011) Public understanding of solar radiation management. Environ Res Lett 6:044006

Millard-Ball A (2012) The Tuvalu Syndrome: can geoengineering solve climate's collective action problem? Clim Change 110:1047-1066

Owen R (2014) Solar radiation management and the governance of hubris. In: Harrison R, Hester R (eds) Geoengineering of the climate system. Royal Society of Chemistry, London, pp 211-247

Pindyck RS (2017) The use and misuse of models for climate policy. Rev Environ Econ Policy 11:100-114

Ricke KL, Moreno-Cruz JB, Caldeira K (2013) Strategic incentives for climate geoengineering coalitions to exclude broad participation. Environ Res Lett 8:014021
Schäfer S, Low S (2018) The discursive politics of expertise: what matters for geoengineering research and governance? In: Trentmann F, Sum A-B, Rivera M (eds) Work in progress: environment and economy in the hands of experts. Oekom, Munich

Selin C (2008) The Sociology of the future: tracing stories of technology and time. Sociol Compass 2:1878-1895

Shackley S, Wynne B (1996) Representing uncertainty in global climate change science and policy: boundary-ordering devices and authority. Sci Technol Hum Values 21(3):275-302

Stilgoe J, Owen R, Macnaghten P (2013) Developing a framework for responsible innovation. Res Policy 42:1568-1580

Talberg A, Thomas S, Christoff P et al (2018) How geoengineering scenarios frame assumptions and create expectations. Sustain Sci 13:1-12. https://doi.org/10.1007/s11625-018-0527-8

Tavoni M, Socolow R (2013) Modeling meets science and technology: an introduction to a special issue on negative emissions. Clim Change 118:1-14

Urpelainen J (2012) Geoengineering and global warming: a strategic perspective. Int Environ Agreem Polit Law Econ 12:375-389

Van Oudheusden M (2014) Where are the politics in responsible innovation? European governance, technology assessments, and beyond. J Responsib Innov 1:67-86

Vervoort J, Gupta A (2018) Anticipating climate futures in a $1.5^{\circ} \mathrm{C}$ era: the link between foresight and governance. Curr Opin Environ Sustain 31:104-111

Victor DG, Morgan MG, Apt J, Steinbruner J, Ricke KL (2013) The truth about geoengineering: Science fiction and science fact. Foreign Aff 92. https://www.foreignaffairs.com/articles/globa 1-commons/2013-03-27/truth-about-geoengineering. Accessed 29 Apr 2019

Wiertz T (2015) Visions of climate control: solar radiation management in climate simulations. Sci Technol Hum Values 41:438-460

Zürn M, Schäfer S (2013) The paradox of climate engineering. Glob Policy 4:266-277

Publisher's Note Springer Nature remains neutral with regard to jurisdictional claims in published maps and institutional affiliations. 